\title{
The influence of basic beliefs and object-specific attitudes on behavioural intentions towards a rare and little-known amphibian
}

\author{
Rebecca Perry-Hill ${ }^{\mathrm{A}}$, Jordan W. Smith ${ }^{\mathrm{B}}$, Adam Reimer ${ }^{\mathrm{C}}$, Amber S. Mase ${ }^{\mathrm{D}}$, \\ Nathan Mullendore ${ }^{\mathrm{E}}$, Kate K. Mulvaney ${ }^{\mathrm{A}}$ and Linda S. Prokopy ${ }^{\mathrm{A}, \mathrm{F}}$

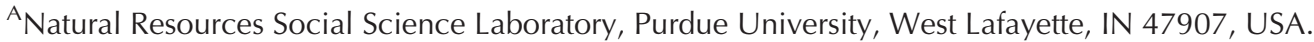 \\ ${ }^{B}$ Center for Geospatial Analytics, NC State University, Raleigh, NC 27695, USA. \\ ${ }^{C}$ Kellogg Biological Station, Michigan State University, Hickory Corners, MI 49060, USA. \\ Department of Forest and Wildlife Ecology, University of Wisconsin-Madison, Madison, WI 53706, USA. \\ ${ }^{E}$ Division of Fish \& Wildlife, Minnesota Department of Natural Resources, New Ulm, MN 56073, USA. \\ FCorresponding author. Email: Iprokopy@purdue.edu
}

\begin{abstract}
Context. Given the decline in amphibian populations worldwide, it is essential to build a better understanding of human behaviours that jeopardise their survival. Much of the literature regarding the social-psychological determinants of behaviours related to wildlife has focussed solely on general wildlife beliefs rather than specific attitudes towards a particular species.

Aims. The goal of this study was to assess how individuals' behavioural intentions towards a rare and little-known species, the hellbender salamander (Cryptobranchus alleganiensis), are influenced by their attitudes towards the animal and their more general beliefs about wildlife.

Methods. Questionnaires were distributed to landowners in Missouri $(n=1065)$ and Indiana $(n=1378)$ in counties where the hellbender is known to exist. A multinomial logit regression model was used to assess the relationship between basic wildlife beliefs, species-specific attitudes and behavioural intentions towards the hellbender.

Key results. The response rate was $36.6 \%$ in Missouri and $41.0 \%$ in Indiana. The more value individuals placed on non-hunting wildlife experiences, the less likely they were to say they would engage in a behaviour harmful to the animal $(\beta=-0.47, P=0.030)$. The more negative the attitudes towards the hellbender held by individuals, the less likely they were to say they would remove the hook $(\beta=-0.55, P<0.001)$, put the animal back $(\beta=-0.77, P<0.001)$, or call a resource professional $(\beta=-0.33, P=0.023)$. A comparison of the Akaike information criterion (AIC) scores and model loglikelihood values without $(\mathrm{AIC}=2$ 858.36; $\mathrm{LLV}=-1$ 395.18) and with $(\mathrm{AIC}=2$ 232.60; $\mathrm{LLV}=-1$ 077.30) the speciesspecific attitude measure showed that its inclusion improved the model.

Conclusions. Positive attitudes towards the hellbender and mutualistic wildlife beliefs were related to non-detrimental behavioural intentions. However, attitudes towards the animal were found to be a stronger and more consistent predictor of behavioural intentions than basic wildlife beliefs.
\end{abstract}

Implications. Efforts to conserve rare or little-known species should focus outreach strategies on developing positive attitudes towards these species, so as to achieve desired changes in behaviour.

Additional keywords: behaviour, conservation, human dimensions.

Received 19 December 2013, accepted 5 September 2014, published online 3 December 2014

\section{Introduction}

Successful conservation requires scientifically valid and economically efficient management approaches, as well as strategies that take into account the prevailing social context (DeCaro and Stokes 2008). The first two requirements for successful species management, scientific grounding and economic feasibility, typically receive the majority of attention from resource managers and policymakers, whereas social and socio-psychological considerations often go unexplored (Stankey and Shindler 2006; Raphael and Molina 2007). For rare and little-known species in particular, a lack of scientific understanding about people's values, attitudes and behaviours can have serious consequences for the long-term success of adopted policies. Conservation initiatives may fail because of the public's lack of support for policies and management actions or engagement in detrimental behaviours towards the species. To this end, more focussed research is needed on the social components of conservation of rare and little-known species.

\section{Theoretical framework}

Although researchers are beginning to examine social factors in the conservation of non-charismatic species (Ressurreição et al. 
2012), human dimensions research often focuses on charismatic megafauna such as wolves (e.g. Williams et al. 2002; Karlsson and Sjöström 2007) and bears (e.g. Gunther et al. 2004; Majić et al. 2011). Conservation and research resources are less commonly allocated to species that are both rare and littleknown (Raphael and Molina 2007). As a result, several researchers have argued that it is important to gain a better understanding of how human attitudes towards less charismatic species influence policy, monetary support and other behavioural decisions that affect the survival of those species (Gunnthorsdottir 2001; Knegtering et al. 2002; Serpell 2004).

As argued by Raphael and Molina (2007), social considerations differ for the conservation of rare and littleknown species as opposed to more charismatic species. Initially, there is a bias towards charismatic species in the selection of conservation targets. For example, Knegtering et al. (2002) found that non-governmental organisation representatives deemed the conservation of birds and mammals as more important than the conservation of 'lower' taxa. In addition, it has been shown that species' attractiveness influences the public's support of conservation measures (Gunnthorsdottir 2001). The attitudinal factors that affect the conservation of rare and little-known species are less understood than those for charismatic species. For example, a large body of research has been devoted to understanding attitudes towards familiar predator species and the effect of those attitudes on individuals' behaviours towards the species (e.g. Musiani and Paquet 2004; Marchini and Macdonald 2012). In contrast, the impacts of attitudes on rare and little-known species, which are presumably weaker and/or less established, are not well understood. Given the decline in amphibian populations worldwide, it is essential that we understand the attitudinal factors leading to the exploitation or persecution of these rare species.

Over the past two decades, the cognitive hierarchy framework has been repeatedly applied and developed in the human dimensions of wildlife literature as a way to link individuals' values to their attitudes and, subsequently, their behaviours (e.g. Fulton et al. 1996; Tarrant et al. 1997; Whittaker et al. 2006; Sijtsma et al. 2012). In the cognitive-hierarchy framework illustrated in Fig. 1, values are the relatively stable and enduring conceptions about what is desirable or undesirable. These values are believed to inform more specific attitudes and behavioural intentions (Rokeach 1979). Because values are poor predictors of behaviour (Fulton et al. 1996), a large body of empirical research has focussed on patterns in basic wildlife beliefs, or wildlife value orientations, as a way of bridging fundamental values with attitudes and behaviours towards wildlife (e.g. Manfredo et al. 2009; Teel et al. 2010; Sijtsma et al. 2012). Building on the work of Fulton et al. (1996), recent studies have suggested that wildlife value orientations are best described by a mutualism-domination continuum (Teel et al. 2007; Manfredo et al. 2009; Teel and Manfredo 2010). Individuals with a strong mutualistic orientation towards wildlife value more appreciative uses of wildlife and believe in the equal rights of animals to exist, whereas those with a strong domination orientation value more consumptive uses of wildlife and believe humans have the right to use and manage wildlife primarily to benefit humans (Manfredo et al. 2009; Teel and Manfredo 2010).

The research cited above has addressed attitudes or behaviours that affect wildlife indirectly. Additionally, measures have focussed on more general attitudes and beliefs towards wildlife and wildlife management practices. As argued by St John et al. (2010), specific attitudes are better predictors of behaviour and therefore are of greater value in planning conservation strategies. We build on past research by using the values-attitude-behaviour model to predict behavioural intentions in the case of direct wildlife encounters. We also strive to establish 'evaluative consistency' across measurements of attitudes and behaviours (Ajzen and Fishbein 2005). In other words, we are assessing attitudes and behaviours towards the same specific object (i.e. the hellbender salamander). This is a slightly different method from the theoretical approach outlined by Ajzen and Fishbein

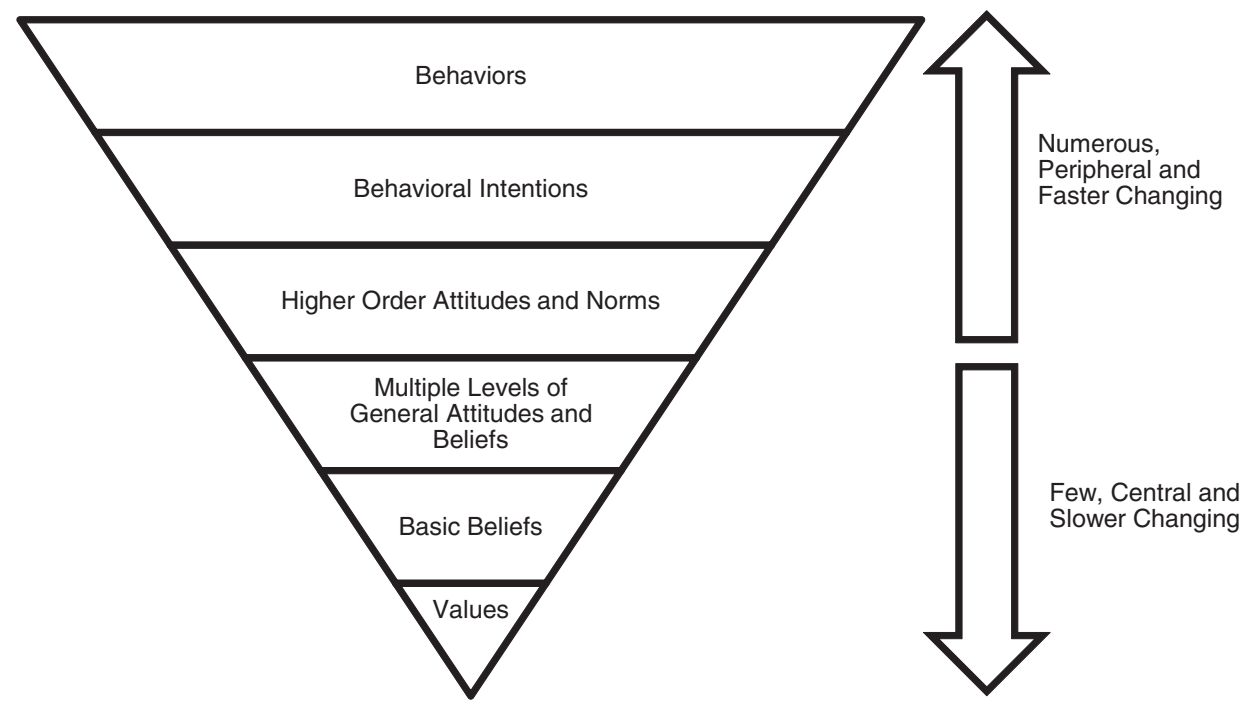

Fig. 1. The cognitive hierarchy model of behaviour (adapted from Fulton et al. 1996). The variables closer to the top are theoretically more closely related to behaviour. 
(2005), where behavioural intentions are related to attitudes towards the behaviour in question, rather than the object of action. Given that individuals can undertake a variety of behaviours when encountering a hellbender in the wild, it seems likely that attitudes towards the animal can serve as a close proxy for attitudes towards the behaviours. For example, people engage in purposeful, direct harms to hellbenders, such as harvesting for pet collection or direct persecution (Briggler et al. 2007; Nickerson and Briggler 2007). In addition, there is anecdotal evidence that anglers who catch or encounter the hellbender react by killing it or throwing it on the river bank (which can harm the animal; Mullendore et al. 2014). Hellbender populations are also threatened by environmental factors, including invasive species, disease and poor water quality (Briggler et al. 2007; Burgmeier et al. 2011). Nevertheless, it is unclear how much of an impact each of these factors has on hellbender populations because few studies have provided empirical evidence (Burgmeier et al. 2011).

Our approach is in direct response to Teel et al.'s (2007) call for 'further examination of wildlife value orientations. . . in relation to more specific attitudes and behaviours' (p. 304). This study advances our understanding of the influence of basic wildlife beliefs relative to species-specific attitudes in determining behavioural intentions. Through the use of a quantitative survey, we explicitly address a critical question in the conservation of rare and little-known species, namely, are individuals' behavioural intentions towards a rare and littleknown species influenced by their attitudes towards the animal and the more general beliefs they hold towards wildlife?

\section{The hellbender: a rare and little-known species}

We focus our research on the hellbender (Cryptobranchus alleganiensis), a rare and little-known amphibian species inhabiting parts of our two study areas, south-eastern Missouri and southern Indiana. In this paper, our focus is on human behaviours that directly contribute to its mortality. Related research on the public's beliefs and familiarity with the hellbender has also been conducted (Mullendore et al. 2014; Reimer et al. 2014). Studies have shown a dramatic decline in amphibian populations throughout the world (Alford et al. 2001; Beebee and Griffiths 2005). The hellbender, a long-lived, large aquatic salamander, endemic to the eastern and central United States, is no exception. The hellbender has suffered severe population declines, with current estimates suggesting an average decrease of $77 \%$ in individual populations between the 1980s and the early 2000s (Wheeler et al. 2003). The Ozark hellbender subspecies (Cryptobranchus alleganiensis bishopi), found only in the North Fork of the White River and a portion of the Black River System in Missouri and Arkansas (Williams et al. 1981), has been listed as Endangered by the US Fish and Wildlife Service (2011). The eastern hellbender(Cryptobranchus alleganiensis alleganiensis) is a farther-ranging (i.e. Mississippi to New York) subspecies, and is generally offered limited protection on a state by state basis.

The ideal behavioural response to encountering a hellbender in the wild is to leave it be and report the encounter to a state natural-resources agency. For anglers who inadvertently catch a hellbender while fishing, the appropriate response is to release the animal back into the water by cutting the line (Unger and Williams 2012). Undesirable, or detrimental, behavioural responses to catching or encountering a hellbender include killing it, taking it home alive, or throwing it on the river bank. Reports of these detrimental behavioural responses are generally anecdotal, and to the authors' knowledge, no empirical studies have been conducted regarding the prevalence of this detrimental behaviour. However, because the hellbender is an increasingly rare, long-lived species with a slow reproductive rate, even low rates of exploitation are likely to result in population extirpation (Unger and Williams 2012).

\section{Hypotheses}

We explicitly tested three hypotheses related to the relationship between individuals' basic beliefs about wildlife, their attitudes towards the hellbender and their behavioural intentions under hypothetical encounters with the animal. These hypotheses are as follows:

(1) Mutualistic-oriented basic wildlife beliefs will be positively related to non-detrimental behavioural intentions in hypothetical encounters with a hellbender.

(2) Positive attitudes towards the hellbender will be positively related to non-detrimental behavioural intentions in hypothetical encounters with a hellbender.

(3) Attitudes will be a more reliable predictor than basic wildlife beliefs of behavioural intentions in hypothetical encounters with a hellbender.

\section{Materials and methods}

\section{Data collection}

Following the five-wave tailored design method (Dillman et al. 2008), we collected data through a mixed-mode (mail and internet) survey in two different locations, namely, the North Fork of the White River watershed in Missouri and the Blue River watershed of Indiana. The five mailings, including (in order) an advance letter with a link to the internet survey, a paper survey, a reminder postcard, a second paper survey, and a final paper survey, stated that university researchers 'are studying public perceptions of the natural resources in the area surrounding the [Blue River area or North Fork of the White River].' Mailings also informed recipients that respondents would have a better than 1 in 100 chance of winning a US\$30 cash prise.

Two slightly different versions of the survey were used in Indiana. One version of the survey included only the statement 'This animal is a hellbender' next to a picture of the animal. The other version stated 'This animal is a Hellbender. It is only found in one place in Indiana: the waters of the Blue River. Without new efforts to protect it, the Hellbender may disappear from Indiana'. The two versions of the survey were used to assess the impacts of information about rarity on individual attitudes (the findings can be found in Reimer et al. 2014). Independent analysis of data collected using both versions of the survey yielded coefficient estimates with identical directionality and nearly identical significance levels. The questions involved in the analysis presented here were exactly the same in all of the surveys.

To ensure an adequate representation of the stakeholders with the most direct impact on hellbender conservation, we sampled the following two populations in each state: watershed residents 
and private riparian landowners. In Missouri, we conducted a random sample of watershed residents $(n=899)$ and a census of all private riparian landowners along the North Fork of the White River in counties where the hellbender is known to exist $(n=166)$. In Indiana, data collection followed an process identical to a random sample of watershed residents $(n=1097)$ and a census of all private Blue River riparian landowners $(n=281)$ in counties where the hellbender is known to exist. In both states, names and addresses of randomly sampled watershed residents were purchased from Survey Sampling International (www. surveysampling.com/), whereas the names and addresses of riparian landowners were collected from online county property-tax records. The two sampling frames were crosschecked before sampling, to ensure that riparian landowners would not be included in the random sample. Indiana surveys were administered in the summer of 2011 and Missouri surveys were administered in the fall of the same year.

\section{Measures}

\section{Basic wildlife beliefs}

To assess general wildlife beliefs, we utilised a modified version of Fulton et al.'s (1996) measurement scale. The scale is intended to gauge basic values that humans hold towards wildlife through 35-statement items. We reduced the number of statement items through factor analysis to 14 , on the basis of pretesting of the instrument in an undergraduate class in an effort to reduce respondent burden and overall survey length. Some of the statements were also reworded to better fit the Midwestern context. The items (e.g. Humans should manage wild animal populations so that humans benefit and Having wildlife around my home is important to me) were measured using a 7-point Likert scale ranging from 1 (strongly disagree) to 7 (strongly agree). Our analysis of the modified measurement scale identified three basic belief dimensions. These are (1) human management of wildlife, (2) non-hunting wildlife experiences and (3) ethics of hunting or fishing. These three belief dimensions assess mutualistic as opposed to domination-type value orientations towards wildlife (Manfredo et al. 2009; Teel and Manfredo 2010). Higher responses to the nonhunting wildlife experiences and ethics-scale items, and lower responses to human management-scale items, indicate a stronger mutualistic value orientation.

Given the construct validity of the basic wildlife belief scale has been consistently demonstrated in previous research (e.g. Kretser et al. 2009; Fix et al. 2010), a confirmatory factor analysis was used to assess the fit of the hypothesised three-factor firstorder structure implied by the scale's items and the basic wildlife belief dimensions they are intended to measure (Table 1). We confirmed the scale's construct validity through assessments of reliability as well as convergent and discriminant validity (Kline 2011). Both survey samples were checked independently. For more information regarding the analysis of scale reliability and validity, see Supplementary Material.

\section{Attitudinal response}

Attitudes towards hellbenders in both Missouri and Indiana were measured through the use of a semantic differential scale (Mehrabian and Russell 1974). Specifically, we used a modified version of companion-animal scale of Poresky et al. (1988). We reduced original 18 measurement items of the scale down to nine, based on our expectations of applicability with the hellbender attitude object (Table 2). The Poresky et al. (1988) scale was developed for measuring attitudes towards pets, with several items assessing attitude dimensions that would not be expected in human-wildlife relationships (e.g. loving to not loving). In addition to the nine scale items from the Poresky et al. (1988) scale, we added two additional adjective pairs, namely hardy to fragile and dangerous to harmless, expecting that they would be related to attitudes towards herpetofauna. All 11 attitude items (e.g. good to bad, important to unimportant, beautiful to ugly) asked respondents to indicate the number that best described their opinion of the hellbender along a 7-point scale. We confirmed the construct validity of the single-factor attitude scale through assessments of reliability (Cronbach's $\alpha$ and reliability coefficients, $m c^{2}$ ) and convergent validity (factor loadings, $\lambda$ ) (Kline 2011). For more information regarding the analysis of scale reliability and validity, see Appendix 1.

\section{Behavioural intentions}

Respondents' behavioural intentions were measured through one multiple-response question, in which respondents could select more than one option. The question stated, 'If I caught [a hellbender] while fishing or during some other outdoor activity, I would. .' Respondents were then given seven nonexclusive potential responses: 'cut the fishing line,' 'remove the hook,' 'put it back where I found it,' 'call a resource professional,' 'throw it on the bank,' 'kill it,' and 'take it home alive.' Respondents were also given an 'other (please specify)' option; however, these infrequent responses are not included in our analysis. For subsequent analysis and interpretation, we collapsed the three categories of 'throw it on the bank,' 'kill it,' and 'take it home alive' into a single dichotomous variable labelled detrimental behaviour. The use of a response variable that included several non-exclusive behaviours allowed us to capture more information about the intentions of individuals than would the traditional approach of eliciting responses about a single behaviour by using an ordinal scale.

\section{Controls}

We solicited responses from individuals regarding typical socio-demographic characteristics (gender, age and education). These measures were included in the model as controls. We also solicited responses regarding whether or not respondents had heard of the hellbender before receiving the survey as well as whether or not they had fished in the previous 12 months. The survey included these questions because these factors might also influence behaviour (e.g. we believed anglers would be more likely to remove a hook from a hellbender because they are more likely to fish). Both of these measures are dichotomous and were included in the model as additional controls.

\section{Modelling behavioural intentions}

The dependent variable, behavioural intentions, contains five non-exclusive response options. Correct and parsimonious model development requires that we account for the nonexclusivity of these response categories (Hartzel et al. 2001; 


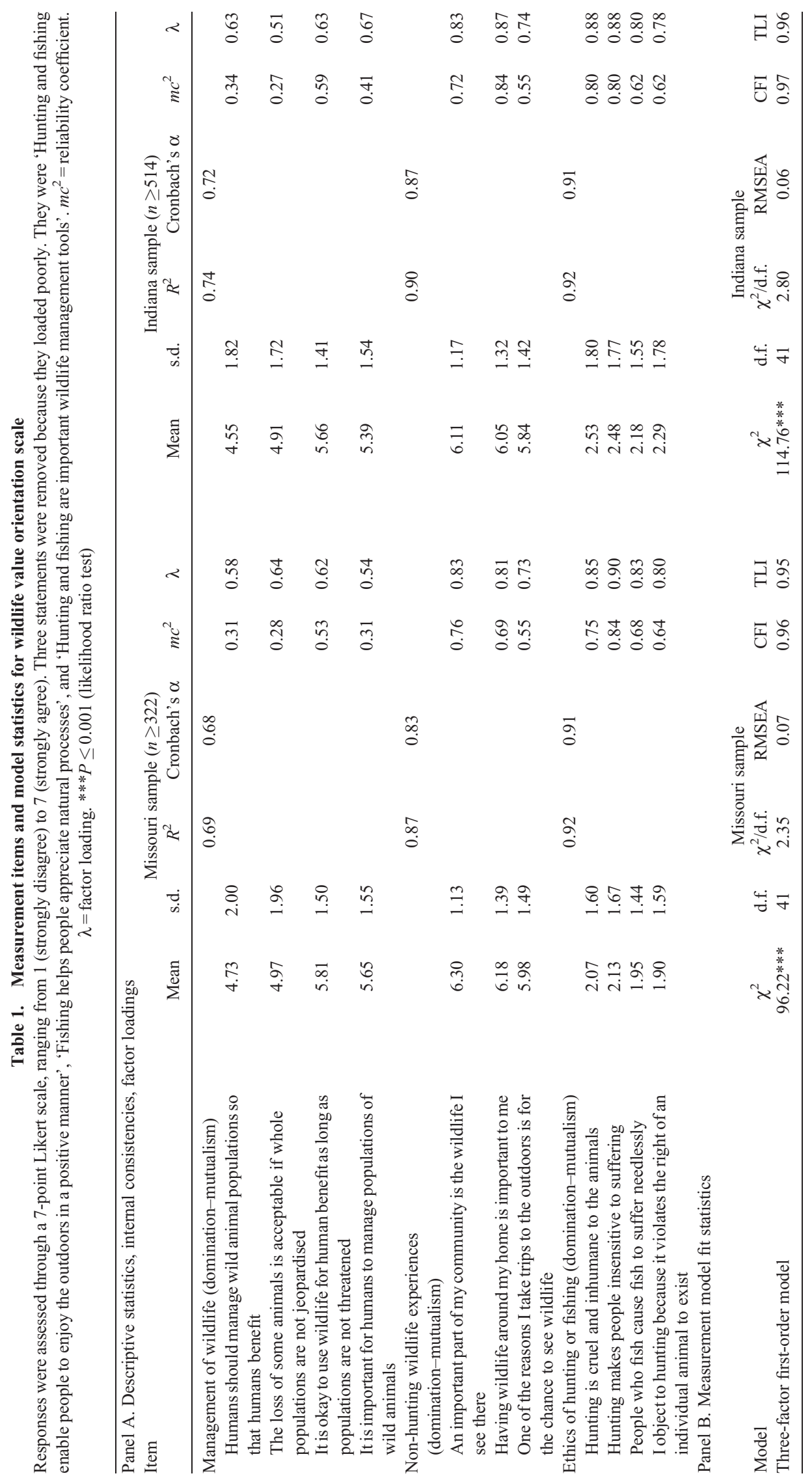


Table 2. Measurement item and model statistics for attitudinal response scale Responses were assessed through a 7-point semantic differential scale where lower values generally indicate more positive attitudes. However, some of the measurement items assess attitudinal dimensions that are not clearly positive or negative (e.g. hardy to fragile)

\begin{tabular}{|c|c|c|c|c|c|c|c|c|c|c|}
\hline \multirow[t]{2}{*}{ Item } & \multicolumn{5}{|c|}{ Missouri sample } & \multicolumn{5}{|c|}{ Indiana sample } \\
\hline & Mean & s.d. & Cronbach's $\alpha$ & $m c^{2}$ & $\lambda$ & Mean & s.d. & Cronbach's $\alpha$ & $m c^{2}$ & $\lambda$ \\
\hline Attitudinal response & & & 0.90 & & & & & 0.90 & & \\
\hline Good to bad & 2.67 & 1.70 & & 0.70 & 0.78 & 3.33 & 1.77 & & 0.81 & 0.85 \\
\hline Important to unimportant & 2.76 & 1.82 & & 0.81 & 0.84 & 3.30 & 1.88 & & 0.79 & 0.82 \\
\hline Beautiful to ugly & 4.14 & 2.05 & & 0.23 & 0.58 & 5.21 & 1.85 & & 0.32 & 0.65 \\
\hline Friendly to not friendly & 3.73 & 1.70 & & 0.28 & 0.64 & 4.46 & 1.70 & & 0.36 & 0.70 \\
\hline Warm to cold & 4.58 & 1.75 & & 0.09 & 0.42 & 5.00 & 1.60 & & 0.16 & 0.52 \\
\hline Pleasant to unpleasant & 3.70 & 1.66 & & 0.39 & 0.73 & 4.64 & 1.72 & & 0.46 & 0.80 \\
\hline Valuable to worthless & 2.87 & 1.87 & & 0.82 & 0.86 & 3.46 & 1.87 & & 0.74 & 0.80 \\
\hline Clean to dirty & 2.98 & 1.70 & & 0.65 & 0.82 & 4.19 & 1.82 & & 0.46 & 0.71 \\
\hline Hardy to fragile & 4.47 & 1.94 & & - & - & 3.74 & 1.77 & & - & - \\
\hline Harmless to dangerous & 2.23 & 1.67 & & 0.34 & 0.59 & 3.10 & 1.77 & & 0.49 & 0.67 \\
\hline Dry to slimy & 5.15 & 1.56 & & - & - & 5.66 & 1.45 & & - & - \\
\hline
\end{tabular}

Skrondal and Rabe-Hesketh 2004). To accomplish this, we utilised a multinomial logit regression model that generalises the logistic regression model to account for more than one outcome (McFadden 1974). We set up the data by creating a unique observation for each respondent and each behavioural choice. This process, referred to as exploding or expanding the dataset results in a panel dataset with $x$ panels that directly correspond to $x$ response categories. For our analysis, five panels were created. As a result, the dependent-variable behaviour is specific to individual respondents $i$, and behaviour $b$. Because we needed to generate inference about the effect of each independent variable on each behavioural intention, we created a dummy variable corresponding to each panel as well as interactions between each panel (potential behaviour) and each independent variable. By doing so, the model is effectively estimating five logistic regression models at once. However, the multinomial logit model controls for within-subject correlation across dependent variables (Hartzel et al. 2001; Skrondal and Rabe-Hesketh 2004).

After generating the factor scores for basic wildlife belief dimensions (BasicWildlifeBelief1, BasicWildlifeBelief2, BasicWildlifeBelief3) and attitudinal responses $(A R)$, and including controls for prior knowledge of the species, fishing behaviour, gender, age and education, our full model of behavioural intentions is specified as

$$
\begin{aligned}
\text { behavior }_{i b}= & \mu+\beta_{1}{\text { BasicWildlifeBelief } 1_{i b}} \\
& +\beta_{2}{\text { BasicWildlifeBelief } 2_{i b}} \\
& +\beta_{3}{\text { BasicWildlifeBelief } 3_{i b}} \\
& +\beta_{4} \text { AR }_{i b} \\
& +\beta_{5} \text { HeardOfHellbenderBefore }_{i b} \\
& +\beta_{6} \text { Angler }_{i b} \\
& +\beta_{7} \text { gender }_{i b} \\
& +\beta_{8} \text { age }_{i} \\
& +\beta_{9} \text { education }_{i} \\
& +\varepsilon_{i b}
\end{aligned}
$$

Note that we included a random effect for the sample from which the data were generated, either Missouri or Indiana. Inclusion of the random effect implies that we were allowing the regression intercepts to vary across samples; however, the slopes were the same. We included the random effect in an effort to control for potential variation in responses among samples. To preview the findings, we found the random effect to be non-significant, indicating no variation across samples.

Given that our hypotheses called for an examination of the relationship between both basic wildlife beliefs and attitudinal responses on behavioural intentions, we first estimated the model above without the attitudinal response variable, generating an Akaike information criterion (AIC) score. We subsequently estimated the full model, with the attitudinal response variable included, and compared its AIC against the first model. Higher AIC scores reflect a model that is more likely to minimise information loss. The models were estimated using the xtmelogit command in Stata 12.0 (StataCorp, College Station, TX).

\section{Results}

\section{Sample descriptions}

In total, 348 responses were received from residents living in the Ozarks watershed of Missouri; this included 243 individuals who were randomly sampled and 105 riparian landowners. In total, 113 surveys were returned undeliverable, yielding a total adjusted response rate of $36.6 \%$. The majority of respondents were male $(68.0 \%)$. The mean age was 61.0 years $($ s.d. $=13.0)$ and $24.8 \%$ indicated they had obtained a 4-year college degree or a graduate degree. A majority of Missouri respondents $(83.2 \%)$ were familiar with the hellbender before taking the survey. More than half (63\%) of the Missouri survey respondents reported fishing in the past year.

For the surveys administered in the Blue River watershed of Indiana, 541 were completed and returned successfully (388 from the random sample and 155 from riparian land owners). After accounting for undeliverable surveys (58), this tabulates out to a response rate of $41.0 \%$. The majority of Indiana 
respondents were male $(63.4 \%)$, the mean age was 58.6 (s.d. $=14.5$ ), and $22.7 \%$ indicated they had obtained either a 4-year college or graduate degree. In all, $45.1 \%$ of Indiana respondents were familiar with the hellbender before taking the survey. More than half $(51 \%)$ of the Indiana survey respondents reported fishing in the past year.

\section{Basic wildlife beliefs}

Descriptive statistics for the basic wildlife belief statement items are shown in Table 1. On average, Missouri respondents strongly valued non-hunting wildlife experiences, while also believing that hunting and fishing are ethical. Respondents also slightly favoured human-centred management of wildlife because average responses to the first four statement items were all above the scale midpoint of 4 . The descriptive statistics for the Indiana sample revealed similar, yet slightly weaker, patterns of basic wildlife beliefs.

\section{Behavioural intentions}

The distribution of respondents' behavioural intentions was similar in Missouri and Indiana. Most individuals, $74.4 \%$ of the Missouri sample and $71.6 \%$ of the Indiana sample, indicated that they would put a hellbender back where it was found if they were to catch one. About half of respondents, $50.9 \%$ of the Missouri sample and $44.2 \%$ of the Indiana sample, indicated that they would remove the hook. Only about one-fifth of the respondents indicated that they would cut the line and even fewer indicated that they would call a resource professional. Very few individuals, $2.3 \%$ of the Missouri sample and $4.4 \%$ of the Indiana sample, indicated that they would either 'throw it on the bank' 'kill it' or 'take it home alive'.

\section{Regression results}

We first estimated the regression model without the latent attitudinal response variable and then re-estimated the model with it included as a predictor of behavioural intentions. A comparison of the AIC scores and model log-likelihood values without $(\mathrm{AIC}=2858.36 ; \mathrm{LLV}=-1395.18)$ and with $(\mathrm{AIC}=2232.60 ; \mathrm{LLV}=-1077.30)$ showed that inclusion of the attitudinal response measure improved the model. Subsequently, we present results for only the model with the attitudinal response measure included (Table 3). Output from the reduced model is included in Table S1 (available as Supplementary Material for this paper) for reference.

\section{Basic wildlife beliefs}

Results from the full regression model suggest that basic wildlife beliefs are poorer predictors of individuals' behavioural intentions than are attitudinal responses towards the animal. For all the combinations across the three latent basic wildlife belief dimensions and the five behaviours, only two significant relationships were present (Table 3, Fig. S1, available as Supplementary Material for this paper). First, the data showed that the more value individuals placed on nonhunting wildlife experiences, the more likely they were to say they would put a hellbender back if they encountered it while fishing $(\beta=0.32, P=0.014)$. Second, the data suggested that the more value individuals placed on non-hunting wildlife experiences, the less likely they were to say they would engage in a behaviour harmful to the animal (either throwing it on the bank, killing it, or taking it home alive) $(\beta=-0.47, P=0.030)$. These significant results are highlighted in Fig. $\mathrm{S} 1 b$.

It is important to note here that although only two basic wildlife beliefs were significantly related to behavioural intentions, both relationships provided support for Hypothesis 1. Explicitly, the results suggested that more mutualistic-oriented basic wildlife beliefs are positively related to non-detrimental behavioural intentions in hypothetical encounters with a hellbender. Consequently, we fail to reject Hypothesis 1 .

\section{Attitudinal response}

Individuals' attitudinal responses towards the animal were a consistent and significant predictor of behavioural intentions. First, the data suggested the more negative the attitudes held by individuals, the less likely they were to say they would remove the hook $(\beta=-0.55, P<0.001)$, put the animal back $(\beta=-0.77, P<0.001)$, or call a resource professional $(\beta=-0.33, P=0.023)$. These significant results are illustrated in Fig. 2; the attitudinal response scale ranges from positive to negative and the coefficients should be interpreted accordingly. Each of these significant results supports the expected outcomes noted in Hypothesis 2. The data suggest that positive attitudes towards the hellbender are positively related to non-detrimental behavioural intentions (the data also suggest that the inverse is true). Given this, we fail to reject Hypothesis 2.

\section{Comparison of independent variables}

A visual comparison of effect-size measures and significance levels between the independent basic wildlife belief and attitude variables, as well as the noted lower AIC value for the model including the attitude measure, showed that speciesspecific attitudes are stronger and more consistent predictors of behavioural intentions than are basic wildlife beliefs. Consequently, we fail to reject Hypothesis 3.

\section{Controls}

The analysis also revealed that individuals already familiar with the hellbender were more likely to indicate that they would remove the hook if they caught one $(\beta=0.74, P<0.001)$. Not surprisingly, the same was true for anglers $(\beta=0.58, P=0.005)$. None of the other socio-demographic characteristics had a significant influence on behavioural intentions.

\section{Discussion}

We began this investigation with a desire to examine whether or not individuals' behavioural intentions towards hellbenders are influenced by both their attitudes towards the animal and their more general beliefs about wildlife. On the basis of a review of related literature, we posed three distinct hypotheses, all of which were supported by our empirical investigation. Support for these hypotheses, along with our relatively unique approach to measuring both attitudes and behavioural intentions, 
R. Perry-Hill et al.

Table 3. Results from mixed-effects logistic regression panel model

Model log-likelihood $=-1077.30$, Akaike information criterion $=2232.60$, Bayesian information criterion $=2460.97$. $\mathrm{M}-\mathrm{D}$, indicates an orientation continuum from mutualism to domination. $\mathrm{D}-\mathrm{M}$, indicates an orientation continuum from domination to mutualism. ${ }^{* * *} P \leq 0.001 ;{ }^{* *} P \leq 0.01 ; * P \leq 0.05$

\begin{tabular}{|c|c|c|c|c|c|}
\hline \multirow[t]{2}{*}{ Behaviour and covariate } & \multirow[t]{2}{*}{ Coef. } & \multirow[t]{2}{*}{ s.e. } & \multirow[t]{2}{*}{$z$} & \multicolumn{2}{|c|}{$95 \%$ CI } \\
\hline & & & & LB & UB \\
\hline \multicolumn{6}{|l|}{ Cut the Line } \\
\hline Management of wildlife (M-D) & 0.27 & 0.16 & 1.72 & -0.04 & 0.58 \\
\hline Non-hunting wildlife experiences (D-M) & 0.05 & 0.14 & 0.38 & -0.22 & 0.32 \\
\hline Ethics of hunting or fishing (D-M) & 0.07 & 0.14 & 0.48 & -0.20 & 0.33 \\
\hline Attitudes & 0.20 & 0.12 & 1.71 & -0.03 & 0.43 \\
\hline Heard of hellbender before & 0.17 & 0.24 & 0.72 & -0.30 & 0.64 \\
\hline Angler & 0.42 & 0.24 & 1.72 & -0.06 & 0.90 \\
\hline \multicolumn{6}{|l|}{ Remove the hook } \\
\hline Management of wildlife (M-D) & 0.00 & 0.13 & -0.03 & -0.27 & 0.26 \\
\hline Non-hunting wildlife experiences (D-M) & 0.03 & 0.12 & 0.25 & -0.20 & 0.26 \\
\hline Ethics of hunting or fishing (D-M) & 0.06 & 0.12 & 0.48 & -0.18 & 0.29 \\
\hline Attitudes & $-0.55^{* * *}$ & 0.11 & -5.06 & -0.77 & -0.34 \\
\hline Heard of hellbender before & $0.74 * * *$ & 0.20 & 3.66 & 0.34 & 1.14 \\
\hline Angler & $0.58 * *$ & 0.20 & 2.83 & 0.18 & 0.98 \\
\hline \multicolumn{6}{|l|}{ Put it Back } \\
\hline Management of wildlife (M-D) & 0.15 & 0.17 & 0.87 & -0.18 & 0.48 \\
\hline Non-hunting wildlife experiences (D-M) & $0.32 * *$ & 0.13 & 2.47 & 0.07 & 0.58 \\
\hline Ethics of hunting or fishing (D-M) & 0.27 & 0.16 & 1.74 & -0.03 & 0.58 \\
\hline Attitudes & $-0.77 * * *$ & 0.14 & -5.57 & -1.04 & -0.50 \\
\hline Heard of hellbender before & 0.33 & 0.25 & 1.32 & -0.16 & 0.83 \\
\hline Angler & -0.13 & 0.26 & -0.49 & -0.64 & 0.38 \\
\hline \multicolumn{6}{|l|}{ Call a resource professional } \\
\hline Management of wildlife (M-D) & -0.19 & 0.17 & -1.16 & -0.52 & 0.13 \\
\hline Non-hunting wildlife experiences (D-M) & 0.20 & 0.18 & 1.10 & -0.15 & 0.55 \\
\hline Ethics of hunting or fishing (D-M) & 0.22 & 0.15 & 1.51 & -0.07 & 0.52 \\
\hline Attitudes & $-0.33^{*}$ & 0.15 & -2.28 & -0.62 & -0.05 \\
\hline Heard of hellbender before & 0.11 & 0.29 & 0.39 & -0.45 & 0.68 \\
\hline Angler & 0.39 & 0.29 & 1.33 & -0.19 & 0.96 \\
\hline \multicolumn{6}{|l|}{ Detrimental behaviour } \\
\hline Management of wildlife (M-D) & 0.64 & 0.39 & 1.62 & -0.13 & 1.41 \\
\hline Non-hunting wildlife experiences (D-M) & $-0.47^{*}$ & 0.22 & -2.18 & -0.89 & -0.05 \\
\hline Ethics of hunting or fishing (D-M) & -0.13 & 0.36 & -0.37 & -0.83 & 0.57 \\
\hline Attitudes & 0.40 & 0.26 & 1.53 & -0.11 & 0.92 \\
\hline Heard of hellbender before & 0.04 & 0.53 & 0.08 & -1.00 & 1.08 \\
\hline Angler & -0.34 & 0.53 & -0.64 & -1.37 & 0.70 \\
\hline \multicolumn{6}{|l|}{ Socio-demographic characteristics } \\
\hline Gender & -0.13 & 1.41 & -0.13 & -0.03 & 0.48 \\
\hline Age & -0.89 & -0.05 & -0.89 & -0.01 & 0.00 \\
\hline Education & -0.83 & 0.57 & -0.83 & -0.05 & 0.08 \\
\hline \multicolumn{6}{|l|}{ Panel variables } \\
\hline Cut the line & 0.53 & 0.37 & 1.41 & -0.20 & 1.26 \\
\hline Remove the hook & $1.58 * * *$ & 0.35 & 4.54 & 0.90 & 2.26 \\
\hline Put it back & $3.78 * * *$ & 0.38 & 10.01 & 3.04 & 4.52 \\
\hline Detrimental behaviours & $-1.29 *$ & 0.60 & -2.16 & -2.45 & -0.12 \\
\hline Call a professional & & & 0.00 (omitted) & & \\
\hline Constant & $-2.21 * * *$ & 0.40 & -5.56 & -2.99 & -1.43 \\
\hline Random effects parameters & & Estimate & & & \\
\hline Sample & & $2.42 \mathrm{e}^{-7}$ & & & \\
\hline
\end{tabular}

yield three contributions to the human dimensions of wildlife literature. Specifically, these contributions are as follows:

(1) further support for the proposition that attitudes are more consistent at predicting behavioural intentions than are more general basic wildlife beliefs,
(2) support for previous calls for 'evaluative consistency' between attitudinal and behavioural measures,

(3) information about attitudes and beliefs that can guide the conservation of hellbenders and other species affected by exploitation and persecution. 


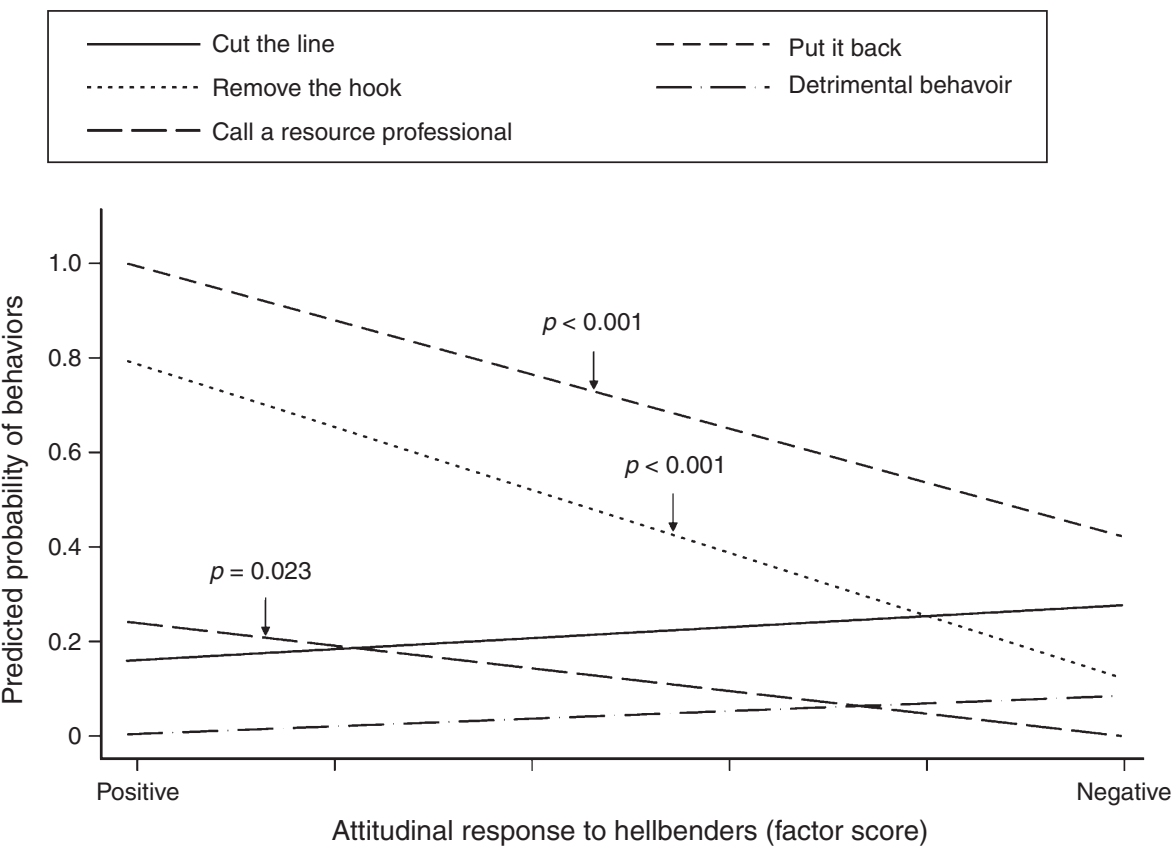

Fig. 2. Predicted probabilities of behavioural intentions in response to catching a hellbender relative to attitudinal responses towards the animal. All predicted probabilities are estimated at the means of all other covariates in the final model (i.e. all other independent variables are being held constant).

\section{Basic wildlife beliefs, attitudes and behavioural intentions}

The responses to the basic wildlife belief scales indicate that residents in the study areas possess both mutualistic and domination value orientations. Many respondents appear to value both hunting (domination oriented) and non-hunting (mutualism oriented) experiences with wildlife. Among respondents, there was widespread variability in beliefs about the ethics of hunting and fishing questions, which were all posited with a strong mutualistic tone (e.g. hunting is cruel and inhumane to the animals). The strong agreement with the human-centred questions in the wildlife management scale suggests a strong domination value orientation in regards to this belief dimension.

Similar to previous empirical studies on value-attitudebehaviour relationships pertaining to wildlife or wildlife management, we found that basic wildlife beliefs were neither as consistent nor as strong predictors of behavioural intention as were attitudes. This finding has become a 'central concept' within the values-attitudes-behaviours literature; we add to this literature by extending the framework to a rare and littleknown species of conservation concern (Manfredo et al. 2004). Generally, it is assumed that the more direct correspondence there is between variables (in terms of target, action, context or time), the stronger the relationship between those variables. For example, Whittaker et al. (2006) found a weaker relationship between respondents' general wildlife beliefs and their support for specific wildlife-management actions when compared with general management actions. More explicitly, basic wildlife beliefs have relatively little impact on specific behaviours after accounting for the more significant influence of attitudes. In this study, attitudes towards the hellbender had a greater influence on specific behavioural intentions than had basic wildlife beliefs.

Understanding stakeholders' basic wildlife beliefs, speciesspecific attitudes, and their relationship to behaviour are important to the conservation of rare and little-known species. Past research has shown that attitudes mediate the relationship between basic beliefs and behavioural intentions (Fulton et al. 1996; Vaske and Donnelly 1999). Furthermore, the theory of cognitive dissonance (Festinger 1957) posits that people prefer to behave in ways that are consistent with their beliefs and attitudes. This theory helps explain why respondents who value non-hunting wildlife experiences are less likely to say that they would engage in a behaviour that would harm a hellbender. The theory of cognitive dissonance also suggests that the public is more likely to support conservation efforts if the broader goals align with the public's values as expressed through their basic beliefs about wildlife. Because basic beliefs are more stable than attitudes (Rokeach 1979; Fulton et al. 1996), outreach is not likely to be a viable strategy in changing general beliefs about wildlife. Therefore, knowing that stakeholders in Missouri and Indiana value both hunting and non-hunting experiences with wildlife, as well as human management of wildlife, can help planners articulate the goals and objectives of hellbender conservation in a way that fits with the public's beliefs. Furthermore, our findings provided support for the idea that changing basic wildlife beliefs is not likely to have a direct effect on behaviour (Fulton et al. 1996). Because attitudes are less stable and more closely related to behaviour 
than are basic beliefs, outreach efforts should focus on promoting positive attitudes towards hellbenders.

\section{Evaluative consistency}

Our unique conceptualisations and measurements of both attitudes and behavioural intentions allow us to generate more definitive and explicit inferences regarding the connections among beliefs, attitudes and behavioural intentions. This contribution is important to the field of wildlife conservation because it helps inform how future social science research should be conducted so that it is more useful for those leading conservation efforts. No previous study grounded in the cognitive hierarchy framework has assessed how attitudes towards a particular species affect behavioural intentions in direct encounters. Attitudes are generally measured in reference to their influence on the public's acceptance of wildlife-management actions (Zinn and Pierce 2002; Dougherty et al. 2003; Whittaker et al. 2006) or support of conservation (Tarrant et al. 1997; Teel et al. 2010). The fact that this previous research has noted a significant relationship between tangential attitudes and behaviour is somewhat surprising, given the large body of literature on social psychology, suggesting that tangential attitudes are poor predictors of specific behavioural intentions (see Ajzen and Fishbein 2005). However, on closer inspection of this literature, it becomes clear that not only is the measurement of attitudes tangential to the species, so too are the behavioural intentions or behaviours. For example, the behavioural measurement of Teel et al. (2010) was simply engagement in certain recreational activities, none of which is specific to a particular species. Similarly, Dougherty et al. (2003) gauged behaviours through a composite measure of recreational intentions. Our intent is not to criticise prior research, but to highlight the fact that the attitude object is consistent across both measures of attitudes and behaviours in our study, a relatively uncommon approach in the value-attitudebehaviour literature (Whittaker et al. 2006). The result is a consistent and significant relationship between attitudes and behavioural intentions.

It is important to note that our attitude operationalisation was different from the theoretical relationship outlined by Ajzen and Fishbein (2005). The attitude measure in our study assessed respondent evaluation of the hellbender rather than the specific behaviours we investigated. While Ajzen and Fishbein (2005) stated that for attitudes to be predictive of behavioural intentions, they should be closely specified to the behaviour, our findings indicated that in the case of wildlife-specific behaviours, attitudes towards the species can serve as a useful proxy for behaviour-specific attitudes. This finding is useful for conservation efforts, where professionals attempting to understand human dimensions of conservation may not have complete knowledge of relevant behaviours or the time or expertise to carry out a full theory-based exploration of behaviours. The most significant finding for conservation efforts is that positive attitudes towards the conservation target species are related to positive behaviours, allowing professionals on the ground to explore public attitudes as a predictor of behaviour.
When discussing the aforementioned disconnect between general or tangential attitudinal measures and specific behaviours, Ajzen and Fishbein (2005) suggested that researchers attempt to establish 'evaluative consistency' across measurements of attitudes and behaviours. The attitude object, they argued, should be either identical between metrics, or be abstracted to a relatively generalised level (e.g. attitudes and behavioural intentions towards all wildlife as opposed to a particular species). In the literature pertaining to other types of environmentally beneficial behaviours (e.g. recycling and environmental activism), the evidence supports this argument (Heberlein and Black 1976; Vining and Ebreo 1992). The results from the research presented here supported this previously untested proposition within the context of attitudes and behaviours towards wildlife.

\section{Implications for conservation of rare and little-known species}

Through this improved theoretical understanding of the relationship between attitudes and behavioural intentions towards a rare and little-known species, we can inform conservation efforts. Because the data suggested that attitudes towards the animal have a stronger relationship with the intent to harm a hellbender than do general wildlife beliefs, resource managers should focus on outreach strategies that promote positive attitudes towards hellbenders. These findings and our theoretical model could be potentially useful for conservation efforts in other management contexts as well. Understanding the linkage between attitudes and behavioural intentions could be particularly useful in contexts where it is known that people have negative attitudes towards a conservation target species. For example, Knight (2008) found that individuals had more negative attitudes towards snakes, bats and spiders than they did towards animals such as seals, ducks or cats, and that those attitudes had direct and significant impacts on support for conservation actions. Our findings indicated efforts to change attitudes in situations where negative attitudes towards conservation targets abound could be necessary to avoid potentially harmful behaviours by humans. Efforts to conserve rare or little-known species should investigate attitudes towards those species and focus outreach strategies on developing positive attitudes towards the species, so as to achieve desired changes in behaviour. According to Beebee and Griffiths (2005), scientific and social scientific approaches must be joined to address the global threats to amphibians. The conservation of rare and little-known species will likely be more effective if it is informed by collaborative efforts involving empirical social, biological and economic science.

A priority for further research into the human dimensions of rare and little-known species conservation is to determine the role of familiarity on the public's attitudes, as well as to identify effective strategies for promoting attitude change. Because respondents with prior knowledge of the hellbender were more likely to remove the hook, our model provides evidence that familiarity is associated with behaviour that is conducive to conservation. In the case of populations negatively affected by direct exploitation, are people's attitudes determined more by the appearance of the animal or 
familiarity with the species? Can attitudes be easily swayed by information? These questions are worthy of continued rigorous empirical research that could further both our theoretical understanding of the connections among basic wildlife beliefs, attitudes and behaviours, and improve species conservation efforts designed to inform the public about appropriate behavioural responses regarding rare and littleknown species.

\section{Study limitations}

The research presented here is a step towards understanding the connections between cognitive constructs and conservationrelated behaviours. Despite clear support for the three hypotheses proposed in this research, we acknowledge several limitations of the study. The first limitation stems from our survey response rates. A low response rate (below 40\%) is a potential concern in survey research, as it could indicate a biased or unrepresentative sample. Our sample appeared to be biased towards male respondents, although this is unsurprising given our sampling frame of landowners, the majority of whom are male. Additionally, it is not possible to compare our sample to the general population in terms of outdoor recreation behaviours, because we are unaware of sources of information regarding participation rates in outdoor recreation for our survey populations. Although slight, it is possible that some response bias exists and our results may not be generalisable to the entire adult populations of our study areas.

The most significant limitation is that survey research does not allow for the measurement of actual behaviour. In the present study, we asked for self-reports of behavioural intentions in a hypothetical situation. This limitation is not unique to this study, and behavioural intentions have been shown to be a close proxy for behaviour (Fishbein and Ajzen 2010). However, it is worth noting because the correlation among attitudes, intentions and behaviour may be weaker for behaviours that are infrequent or unfamiliar (Heberlein and Black 1976), such as the behaviour that occurs in an encounter with a rare and little-known species. Behavioural theories also note that there are other factors, including one's physical or emotional ability to act that can prevent one from behaving as intended (Fishbein and Ajzen 2010).

Our study included several behaviours believed by local conservation professionals to be potential sources of harm to the hellbender. Many of these behaviours are specific to angling. People may engage in activities such as canoeing or swimming, in which they might encounter the hellbender and interact in ways that we did not explore in this study. The behavioural intentions of respondents who do not fish or recreate outdoors on a regular basis are largely hypothetical and may never translate into actual behaviour. Low familiarity with the hellbender may have also led to respondents providing 'pseudo-opinions' rather than fully formed beliefs or attitudes. Although this can be a problem in survey research in general (Bishop et al. 1980, 1986; Converse 2006), the present study relied primarily on measures with some robustness to this issue. Individuals need not have heard of the animal before to accurately provide answers to questions regarding basic wildlife beliefs or attitudes measured by the semantic differential approach. Moreover, in an actual encounter with a rare and little-known species, the behaviour of an individual who is unfamiliar with the animal will be informed by immediate (not fully formed or well established) attitudes. Nevertheless, for conservationists on the ground, it is important to recognise the difference between hypothetical intentions and actual behaviour.

Many of the behavioural intentions assessed in the present study are undesirable (such as killing or taking the animal home) and respondents may have given a socially desirable response rather than a true reflection of their behavioural intention. Although being undesirable, it should be noted that few of the behaviours noted are illegal; only collecting the animals from the wild to keep as pets is an illegal behaviour (Mullendore et al. 2014). This is a common problem in self report-based research (such as surveys) and may have led to underreporting of detrimental behavioural intentions in our study (Streb et al. 2008). However, on the basis of an examination of the effect of socially desirable responding, Milfont (2009) concluded that 'social desirability concerns do not have a strong effect on the way people respond to questions addressing environmental issues' (p. 268). The impracticality of studying such infrequent behaviour through observation forces us to rely on self-reports. Future research investigating the relationship between attitudes and behaviour towards a conservation target could address these limitations through an experimental research design.

\section{Acknowledgements}

Financial support for this project was provided by the Indiana Department of Natural Resources, Division of Fish and Wildlife - Wildlife Diversity Section, through state wildlife improvement grant E2-07-WD0007. We also acknowledge the support and help of the Purdue Herpetology Laboratory and the Purdue Natural Resource Social Science Laboratory's undergraduate employees.

\section{References}

Ajzen, I., and Fishbein, M. (2005). The influence of attitudes on behavior. In 'The Handbook of Attitudes'. (Eds D. Albarracin, B. T. Johnson and M. P. Zanna.) pp. 173-221. (Erlbaum: Hillsdale, NJ.)

Alford, R. A., Dixon, P. M., and Pechmann, J. H. K. (2001). Ecology: global amphibian population declines. Nature 412, 499-500. doi:10.1038/ 35087658

Beebee, T. J. C., and Griffiths, R. A. (2005). The amphibian decline crisis: a watershed for conservation biology? Biological Conservation 125, 271-285. doi:10.1016/j.biocon.2005.04.009

Bishop, G. F., Oldendick, R. W., Tuchfarber, A. J., and Bennett, S. E. (1980). Pseudo-opinions on public affairs. Public Opinion Quarterly 44, 198-209. doi:10.1086/268584

Bishop, G. F., Tuchfarber, A. J., and Oldendick, R. W. (1986). Opinions on fictitious issues: the pressure to answer survey questions. Public Opinion Quarterly 50, 240-250. doi:10.1086/268978

Briggler, J. T., Utrup, J., Davidson, C., Humphries, J., Groves, J., and Johnson, T. Byers, O. (2007). Hellbender population and habitat viability assessment: final report. IUCN/SSC Conservation Breeding Specialist Group, Apple Valley, MN.

Burgmeier, N. G., Unger, S. D., Sutton, T. M., and Williams, R. N. (2011). Population status of the eastern hellbender (Cryptobranchus alleganiensis alleganiensis) in Indiana. Journal of Herpetology 45, 195-201. doi:10.1670/10-094.1 
Converse, P. E. (2006). The nature of belief systems in mass publics (1964). Critical Review: A Journal of Politics and Society 18, 1-74. doi:10.1080/ 08913810608443650

DeCaro, D., and Stokes, M. (2008). Social-psychological principles of community-based conservation and conservancy motivation: attaining goals within an autonomy-supportive environment. Conservation Biology 22, 1443-1451. doi:10.1111/j.1523-1739.2008.00996.x

Dillman, D. A., Smyth, J. D., and Christian, L. M. (2008). 'Internet, Mail and Mixed-Mode Surveys: the Tailored Design Method.' 3rd edn. (Wiley: New York.)

Dougherty, E. M., Fulton, D. C., and Anderson, D. H. (2003). The influence of gender on the relationship between wildlife value orientations, beliefs and the acceptability of lethal deer control in Cuyahoga Valley National Park. Society \& Natural Resources 16, 603-623. doi:10.1080/089419 20309187

Festinger, L. (1957). 'A Theory of Cognitive Dissonance.' (Row Peterson: Evanston, IL.)

Fishbein, M., and Ajzen, I. (2010). 'Prediction and Change of Behavior: the Reasoned Action Approach.' (Psychology Press: New York.)

Fix, P. J., Teel, T. L., Manfredo, M. J., and Boston, S. S. (2010). Assessing public acceptance of wildlife management trade-offs: a case study of elk and vegetation management in Rocky Mountain National Park, Colorado. Human Dimensions of Wildife 15, 405-417. doi:10.1080/10871209. 2010.503235

Fulton, D. C., Manfredo, M. J., and Lipscomb, J. (1996). Wildlife value orientations: a conceptual and measurement approach. Human Dimensions of Wildlife 1, 24-47. doi:10.1080/10871209609359060

Gunnthorsdottir, A. (2001). Physical attractiveness of an animal species as a decision factor for its preservation. Anthrozoos 14, 204-215. doi:10.27 52/089279301786999355

Gunther, K. A., Haroldson, M. A., Frey, K., Cain, S. L., Copeland, J., and Schwartz, C. C. (2004). Grizzly bear-human conflicts in the Greater Yellowstone ecosystem, 1992-2000. Ursus 15, 10-22. doi:10.2192/15 37-6176(2004)015<0010:GBCITG > 2.0.CO;2

Hartzel, J., Agresti, A., and Caffo, B. (2001). Multinomial logit random effects models. Statistical Modelling 1, 81-102. doi:10.1191/14710820 1128104

Heberlein, T. A., and Black, J. S. (1976). Attitudinal specificity and the prediction of behavior in a field setting. Journal of Personality and Social Psychology 33, 474-479. doi:10.1037/0022-3514.33.4.474

Karlsson, J., and Sjöström, M. (2007). Human attitudes towards wolves, a matter of distance. Biological Conservation 137, 610-616. doi:10.1016/ j.biocon.2007.03.023

Kline, R. B. (2011). 'Principles and Practice of Structural Equation Modeling.' 3rd edn. (Guilford: New York.)

Knegtering, E., Hendrickx, L., Windt, H. J. V. D., and Uiterkamp, A. J. M. S. (2002). Effects of species' characteristics on nongovernmental organizations' attitudes toward species conservation policy. Environment and Behavior 34, 378-400. doi:10.1177/0013916502034 003006

Knight, A. J. (2008). 'Bats, snakes and spiders, oh my!' How aesthetic and negativistic attitudes, and other concepts predict support for species protection. Journal of Environmental Psychology 28, 94-103. doi:10.10 16/j.jenvp.2007.10.001

Kretser, H. E., Curtis, P. D., and Knuth, B. A. (2009). Landscape, social and spatial influences on perceptions of human-black bear interactions in the Adirondack Park, NY. Human Dimensions of Wildlife 14, 393-406. doi:10.1080/10871200903055318

Majić, A., Marino Taussig de Bodonia, A., Huber, Đ., and Bunnefeld, N. (2011). Dynamics of public attitudes toward bears and the role of bear hunting in Croatia. Biological Conservation 144, 3018-3027. doi:10.1016/j.biocon.2011.09.005

Manfredo, M. J., Teel, T. L., and Bright, A. D. (2004). Applications of the concept of values and attitudes in human dimensions of natural resources research. In 'Society and Natural Resources: a Summary of Knowledge'. (Eds M. J. Manfredo, J. J. Vaske, B. L. Bruyere, D. R. Field and P. Brown.) pp. 271-282. (Modern Litho: Jefferson, MO.)

Manfredo, M. J., Teel, T. L., and Henry, K. L. (2009). Linking society and environment: a multilevel model of shifting wildlife value orientations in the western United States. Social Science Quarterly 90, 407-427. doi:10.1111/j.1540-6237.2009.00624.x

Marchini, S., and Macdonald, D. W. (2012). Predicting ranchers' intention to kill jaguars: case studies in Amazonia and Pantanal. Biological Conservation 147, 213-221. doi:10.1016/j.biocon.2012.01.002

McFadden, D. (1974). Conditional logit analysis of qualitative choice behaviour. In 'Frontiers of Econometrics'. (Ed. P. Zarembka.) pp. 105-142. (Academic Press: New York.)

Mehrabian, A., and Russell, J. A. (1974). 'An Approach to Environmental Psychology.' (MIT Press: Cambridge, MA.)

Milfont, T. L. (2009). The effects of social desirability on self-reported environmental attitudes and ecological behaviour. The Environmentalist 29, 263-269. doi:10.1007/s10669-008-9192-2

Mullendore, N., Mase, A. S., Mulvaney, K., Perry-Hill, R., Reimer, A., Behbehani, L., Williams, R. N., and Prokopy, L. S. (2014). Conserving the eastern hellbender salamander. Human Dimensions of Wildlife 19, 166-178. doi:10.1080/10871209.2014.853221

Musiani, M., and Paquet, P. C. (2004). The practices of wolf persecution, protection and restoration in Canada and the USA. Bioscience 54, 50-60. doi:10.1641/0006-3568(2004)054[0050:TPOWPP]2.0.CO;2

Nickerson, M. A., and Briggler, J. T. (2007). Harvesting as a factor in population decline of a long-lived salamander; the Ozark hellbender, Cryptobranchus alleganiensis bishopi Grobman. Applied Herpetology 4, 207-216. doi:10.1163/157075407781268354

Poresky, R. H., Hendrix, C., Mosier, J. E., and Samuelson, M. L. (1988). The companion animal semantic differential: long and short form reliability and validity. Educational and Psychological Measurement 48, 255-260. doi:10.1177/001316448804800131

Raphael, M. G., and Molina, R. (2007). 'Conservation of Rare or LittleKnown Species: Biological, Social and Economic Considerations.' (Island Press: Washington, DC.)

Reimer, A., Mase, A., Mulvaney, K., Mullendore, N., Perry-Hill, R., and Prokopy, L. (2014). The impact of information and familiarity on public attitudes toward the eastern hellbender. Animal Conservation 17, 235-243. doi:10.1111/acv.12085

Ressurreição, A., Gibbons, J., Kaiser, M., Dentinho, T. P., Zarzycki, T., Bentley, C., Austen, M., Burdon, D., Atkins, J., Santos, R. S., and Edwards-Jones, G. (2012). Different cultures, different values: the role of cultural variation in public's WTP for marine species conservation. Biological Conservation 145, 148-159. doi:10.1016/j.biocon.2011. 10.026

Rokeach, M. (1979). 'The Nature of Human Values.' (The Free Press: New York.)

Serpell, J. A. (2004). Factors influencing human attitudes to animals and their welfare. Animal Welfare (South Mimms, England) 13, 145-151.

Sijtsma, M. T. J., Vaske, J. J., and Jacobs, M. H. (2012). Acceptability of lethal control of wildlife that damage agriculture in the Netherlands. Society \& Natural Resources 25, 1308-1323. doi:10.1080/08941920. 2012.684850

Skrondal, A., and Rabe-Hesketh, S. (2004). 'Generalized Latent Variable Modeling: Multilevel, Longitudinal, and Structural Equation Models.' (CRC Press: Boca Raton, FL.)

St John, F. A. V., Edward-Jones, G., and Jones, J. P. G. (2010). Conservation and human behaviour: lessons from social psychology. Wildlife Research 37, 658-667. doi:10.1071/WR10032

Stankey, G. H., and Shindler, B. (2006). Formation of social acceptability judgments and their implications for management of rare and littleknown species. Conservation Biology 20, 28-37. doi:10.1111/j.15231739.2005.00298.x 
Streb, M. J., Burrell, B., Frederick, B., and Genovese, M. A. (2008). Social desirability effects and support for a female presidential candidate. Public Opinion Quarterly 72, 76-89. doi:10.1093/poq/nfm035

Tarrant, M. A., Bright, A. D., and Cordell, H. K. (1997). Attitudes toward wildlife species protection: assessing moderating and mediating effects in the value-attitude relationship. Human Dimensions of Wildlife $\mathbf{2}$, 1-20. doi:10.1080/10871209709359091

Teel, T. L., and Manfredo, M. J. (2010). Understanding the diversity of public interests in wildlife conservation. Conservation Biology 24, 128-139. doi:10.1111/j.1523-1739.2009.01374.x

Teel, T. L., Manfredo, M. J., and Stinchfield, H. M. (2007). The need and theoretical basis for exploring wildlife value orientations cross-culturally. Human Dimensions of Wildlife 12, 297-305. doi:10.1080/10871200 701555857

Teel, T. L., Manfredo, M. J., Jensen, F. S., Buijs, A. E., Fischer, A., Riepe, C., Arlinghaus, R., and Jacobs, M. H. (2010). Understanding the cognitive basis for human-wildlife relationships as a key to successful protectedarea management. International Journal of Sociology 40, 104-123. doi:10.2753/IJS0020-7659400306

Unger, S. D., and Williams, R. N. (2012). Eastern hellbender: North America's giant salamander. Purdue Extension Publication No. FNR471, 1-8. [Purdue University Extension: West Lafayette, IN.]

US Fish and Wildlife Service (2011). 'Endangered and Threatened Wildlife and Plants; Endangered Status for the Ozark Hellbender Salamander. Federal Register No. 50 CFR Part 17.' (US Department of the Interior: Washington, DC.)
Vaske, J. J., and Donnelly, M. P. (1999). A value-attitude-behavior model predicting wildland preservation voting intentions. Society \& Natural Resources 12, 523-537. doi:10.1080/089419299279425

Vining, J., and Ebreo, A. (1992). Predicting recycling behavior from global and specific environmental attitudes and changes in recycling opportunities1. Journal of Applied Social Psychology 22, 1580-1607. doi:10.1111/j.1559-1816.1992.tb01758.x

Wheeler, B. A., Prosen, E., Mathis, A., and Wilkinson, R. F. (2003). Population declines of a long-lived salamander: a 20+-year study of hellbenders, Cryptobranchus alleganiensis. Biological Conservation 109, 151-156. doi:10.1016/S0006-3207(02)00136-2

Whittaker, D., Vaske, J. J., and Manfredo, M. J. (2006). Specificity and the cognitive hierarchy: value orientations and the acceptability of urban wildlife management actions. Society \& Natural Resources 19, 515-530. doi:10.1080/08941920600663912

Williams, R. D., Gates, J. E., Hocutt, C. H., and Taylor, G. J. (1981). The hellbender: a nongame species in need of management. Wildlife Society Bulletin 9, 94-100.

Williams, C. K., Ericsson, G., and Heberlein, T. A. (2002). A quantitative summary of attitudes toward wolves and their reintroduction (1972-2000). Wildlife Society Bulletin 30, 575-584.

Zinn, H. C., and Pierce, C. L. (2002). Values, gender, and concern about potentially dangerous wildlife. Environment and Behavior 34, 239-256. doi:10.1177/0013916502034002005 